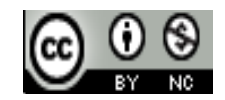

Journal of Education, Teaching, and Learning is licensed under

A Creative Commons Attribution-NonCommercial 4.0 International License.

\title{
Personality FaCtors and Job SATISFACTION: Evaluating THE MEDIATORY ROLE OF EMOTIONAL INTELLIGENCE
}

\author{
Aida Mehrad \\ Universiti Putra Malaysia, Selangor, Malaysia \\ E-mail: mehrad.aida@gmail.com
}

\begin{abstract}
According to the importance of academic staff job satisfaction at university and evaluating effective factors on satisfaction, the present study is to clarify the relationship between personality factors and job satisfaction by the mediatory role of emotional intelligence. The study involved 440 academic staff selected by multi-stage sampling from public research universities in Klang Valley, Malaysia. This study applied a cross-sectional design. Big Five Inventory (BFI), Emotional Intelligence Test (SSEIT), and Job Descriptive Index (JDI) have been used to measured variables of the study. Additionally, the Pearson correlation coefficient, multiple linear regression analysis, and mediation analysis (Sobel test) are used for data analysis. The findings released a positive correlation between emotion perception, utilization of emotion, managing own emotions, managing others' emotions, conscientiousness, agreeableness, and openness with job satisfaction. Conversely, there is a negative correlation between neuroticism and job satisfaction, whereas no correlation is observed between extraversion and job satisfaction. Personality factors likewise showed a significant relationship with almost all emotional intelligence factors except the utilization of emotion and neuroticism. The utilization of emotion and neuroticism predicted the level of job satisfaction, and only utilization of emotion significantly mediated the relationships between agreeableness, conscientiousness, and openness with job satisfaction. In fact, the agreeableness, conscientiousness, and openness academic staff have a better ability to apply emotion to obtain job satisfaction than other staff. In short, the study sheds new light in the context of psychology, particularly in the job satisfaction context among academic staff at universities.
\end{abstract}

Keywords: Academic Staff; Emotional Intelligence; Job Satisfaction; Personality Factors

\section{INTRODUCTION}

As one of the main human resources, the academic staff has a considerable contribution to developing outcomes of the university. Furthermore, attention to their requirements significantly impacts performance, responsibility, relation, behavior, and tendency to continuing work. In fact, academic staff is vital members of the universities, and their scientific knowledge has a considerable effect on the university's outcome (Noordin \& Jusoff, 2009). Truly, job satisfaction is determined as one of the crucial factors in educational organizations, specifically universities; further, realizing effective factors that have relationships with job satisfaction and influence on staff's feeling and perspective regarding their occupation and the environment is imperative (Dawal \& Taha, 2006). Moreover, job satisfaction as an important factor amongst academic staff improves the learning environment and increases its scientific outcomes. Therefore, a high level of job satisfaction would lead to lower turnover and absenteeism (Wan Ahmad \& Abdurahman, 2015). While the low job satisfaction level is one of the main organizational obstacles assumed to be an impendent factor that impacts academic staff performance at universities (Noordin \& Jusoff, 2009). Moreover, it should be considered carefully to control and reduce various negative views toward a workplace by managers or any person in charge (Malik et al., 2010; Dizgah, Chegini, \& Bisokhan, 2012). Generally, the tough conditions may cause low job satisfaction levels among academic staff and reduce their university presentation and achievement. This factor would also lead to a lower amount of academic staff's efficiency and has an unpleasant impact on organizational outcomes (Altbach, Reisberg, \& Rumbly, 2009). In this case, considering and evaluating internal and external factors that influence job satisfaction levels can be valuable, and it creates a precise way for superior organizational performance. This important, current study concentrated on personality factors and emotional intelligence as two essential factors influencing academic staff job satisfaction.

Personality is a collection of behaviors, feelings, emotions, and responses demonstrated by individuals in private and 
social life; it also affects job satisfaction and leads to various reactions and behaviors at work (Bockhaus, Hillyer, \& Peterson, 2012). Personality factors comprised extraversion, neuroticism, agreeableness, conscientiousness, and openness influence staff satisfaction (Therasa \& Vijayabanu, 2014); correspondingly, these factors assumed as essential characteristics between individuals that are noted by other individuals in society (Nasir et al., 2011). These five personality factors are assumed to be well-organized factors that have associations with job satisfaction in the work environment (Ayan \& Kocacik, 2010). According to previous investigations, Fayombo (2010) explained that neuroticism is directly associated with low levels of motivations and emotions; conscientiousness, agreeableness, extraversion, and openness are linked positively with job satisfaction. Mhlanga (2012) likewise found that openness and conscientiousness positively correlate with job satisfaction; on the other hand, neuroticism negatively associates with this organizational factor. Similarly, Ganu and Kogutu (2014) and Ijaz and Khan (2015) emphasized the negative role of neuroticism with job satisfaction among staff in the work environment. The researchers argued that neuroticism, as a destructive factor has an insufficient role at work, and it is assumed as a poor organizational motivator for job satisfaction. Naz, Rehman, and Saqib (2013) reported a negative correlation between neuroticism and job satisfaction, and conscientiousness is one of the greatest predictors of job satisfaction among employees. Cooper et al. (2014) clarified that agreeableness has a significant role in developing job satisfaction and leads to a positive view of the job and co-workers at the workplace.

Corresponding to the highest role of job satisfaction at university, emotional intelligence is another operative factor affecting job satisfaction. Emotional intelligence is determined as the capacity to identify, assess, and revise the emotions of self and others in private and social life to determine staff performance at work (Harms \& Credé, 2010). Regarding Akintayo and Babalola (2012), emotional intelligence is one of the inner motivators that impact feeling and positively associates with job satisfaction. Jorfi, Yaccob, and Shah (2011) identified emotional intelligence as the main factor that improves job satisfaction among employees. Staff with a higher level of emotional intelligence can manage affairs at work. Emdady and Bagheri (2013) reported that emotional intelligence has a key role in employees' activities; likewise, this factor encourages them to compose better decision-making and managing plans at the workplace. Indeed, the presence of these positive results by emotional intelligence creates job satisfaction at the organization. Likewise, a big group of investigators focused on the relationship between emotional intelligence and job satisfaction amongst staff at the workplace. These researchers are Ismail et al. (2010); Naderi Anari (2012); Psilopanagioti et al. (2012); Mousavi et al. (2012); Shooshtarian, Ameli, and Amini Lari (2013); Kalyanasundaram and Lakshmi (2013); Coetzer (2013); Ashraf et al. (2014); Papathanasiou and Siati (2014) that examined these relationships and reported there is a significant and positive relationship between these two factors.
By the evidence of pre-study results that obstacles found at the research site, this research is necessary. It is important to find how much personality types of staff and their emotions related to their feeling about their job and workplace; furthermore, this study aims to evaluate the relationship of big five personality factors and job satisfaction with the mediatory role of emotional intelligence. Additionally, the research attempted to expose three research questions as follows:

1. Is there a relationship between the big five personality factors, emotional intelligence, and job satisfaction?

2. Do big five personality factors and emotional intelligence account for unique variance in predicting job satisfaction?

3. Does emotional intelligence mediate the relationships between the big five personality factors and job satisfaction?

\section{Methodology}

In the present study, a cross-sectional design with face-toface questionnaires has been applied. This study participants were all academic staff (male and female) who worked in public research universities (UPM, UKM, and UM) in Klang Valley, Malaysia. Based on the latest statistics that were provided by MOHE, the total population of academic staff at public research universities in Klang Valley is 6044; based on Krejcie and Morgan Table; the sample size is 361 academic staff. The sample size avoids any sampling error and provides further precise expanded by $20 \%$, and 440 academic staff has selected. Additionally, the multi-stage sampling technique is employed for collecting the data.

\section{A. Measurements}

\section{1) Job Satisfaction}

Job satisfaction measured by JDI was introduced by Brodke et al. (2009) to identifying the work environment, job content, and work technologist. This questionnaire included 72 items with a 3-point scale and measures the amount of job satisfaction among academic staff with five dimensions of work, pay, promotions, supervision, and co-workers (Smith, Kendall, \& Hulin, 1969; Bond, 2013; King, 2014).

\section{2) Big Five Personality Factors}

Big five personality factors relate to the score of staff on BFI offered by John and Srivastava (1999). Next, it was renewed by John, Naumann, and Soto (2008). This inventory assesses five factors of personality by 44 questions, 5 points Likert Scale. These factors comprised extraversion, agreeableness, conscientiousness, openness, and neuroticism (John, Donahue, \& Kentle, 1991).

\section{3) Emotional Intelligence}

Emotional intelligence refers to the staff's score SSEIT proposed by Schutte, Malouff, \& Bhullar (2009). This test attempts to assess emotional intelligence with four factors and has 33 items. These four factors involve the perception of emotion, managing emotions, managing others' emotions, and utilization of emotion (Schutte \& Malouff, 2011). 


\section{B. Data Analyzing}

In this study, for measuring the mediatory role of emotional intelligence on the relationship between personality factors and job satisfaction, Pearson Correlation Coefficient Analysis, Multiple Linear Regression Analysis, and Mediation Analysis (Sobel Test) have been used.

\section{RESULTS AND DISCUSSION}

\section{A. Results}

To answering research question 1, the Pearson correlation coefficient analysis has been used.

TABLE I

CORRELATION OF ALL VARIABLES

\begin{tabular}{|c|c|c|c|c|c|c|c|c|c|c|}
\hline Variable & 1 & 2 & 3 & 4 & 5 & 6 & 7 & 8 & 9 & 10 \\
\hline \multicolumn{11}{|l|}{1 Job Satisfaction } \\
\hline 2 Extraversion & .045 & & & & & & & & & \\
\hline 3 Neuroticism & $-.205 * *$ & $-.346 * *$ & & & & & & & & \\
\hline 4 Agreeableness & $.122 *$ & $.233 * *$ & $-.402 * *$ & & & & & & & \\
\hline 5 Conscientiousness & $.123 *$ & $.393 * *$ & $-.496 * *$ & $.510 * *$ & & & & & & \\
\hline 6 Openness & $.117 *$ & $.398 * *$ & $-.277 * *$ & $.333 * *$ & $.445 * *$ & & & & & \\
\hline 7 Perception of Emotion & $.113 *$ & $.351 * *$ & $-.222 * *$ & $.373 * *$ & $.391 * *$ & $.429 * *$ & & & & \\
\hline 8 Managing Own Emotions & $.135 * *$ & $.424 * *$ & $-.414 * *$ & $.454 * *$ & $.508 * *$ & $.486 * *$ & $.652 * *$ & & & \\
\hline 9 Managing Others' Emotions & $.098 *$ & $.350 * *$ & $-.227 * *$ & $.435 * *$ & $.434 * *$ & $.399 * *$ & $.649 * *$ & $.661 * *$ & & \\
\hline 10 Utilization of Emotion & $.142 * *$ & $.218 * *$ & -.093 & $.298 * *$ & $.289 * *$ & $.368 * *$ & $.504 * *$ & $.631 * *$ & $.563 * *$ & \\
\hline
\end{tabular}

Note: $* \mathrm{p}<.05, * * \mathrm{p}<.01$

Table I presented that perception of emotion ( $r=.351, p$ $<.01)$, managing own emotions $(r=.424, p<.01)$, managing others' emotions ( $r=.350, p<.01)$, and utilization of emotion $(r=.218, p<.01)$ yielded positively significant relationships with extraversion. Additionally, the results shown that perception of emotion $(r=-.222, p<.01)$, managing own emotions $(r=-.414, p<.01)$, and managing others' emotions $(r=-.227, \quad p<.01)$, generated negative significant relationships with neuroticism. Conversely, there is no significant association between neuroticism and utilization of emotion with $(r=-.093, p=.052)$. Furthermore, findings illustrate that perception of emotion $(r=.373, p<.01)$, managing own emotions $(r=.454, p<.01)$, managing others' emotions $(r=.435, p<.01)$, and utilization of emotion $(r$ $=.298, p<.01)$ have significant positive relationships with agreeableness. As shown, perception of emotion $(r=.391, p$ $<.01)$, managing own emotions $(r=.508, p<.01)$, managing others' emotions ( $r=.434, p<.01)$, and utilization of emotion $(r=.289, p<.01)$ have significant positive associations with conscientiousness. And perception of emotion $(r=.429, p$ $<.01)$, managing own emotions $(r=.486, p<.01)$, managing others' emotions $(r=.399, p<.01)$, and utilization of emotion ( $r=.368, p<.01)$ have significant positive relationships with openness. In addition, findings shown that utilization of emotion was not related to neuroticism ( $r=-.093, p=.052)$. Moreover, the present study did not display the mediation role of utilization of emotion between neuroticism and job satisfaction.

Table I also shown that extraversion was found to has no significant relationship with job satisfaction with $(r=.045$, $p=.346)$. The results revealed that agreeableness $(r=.122, p$ $<.05)$, conscientiousness $(r=.123, p<.05)$, and openness $(r$ $=.117, p<.01$ ) yielded positive significant relationships with job satisfaction, while neuroticism has negative correlation with job satisfaction $(r=-.205, p<.01)$. The results likewise illustrated perception of emotion $(r=.113, p<.05)$, managing own emotions $(r=.135, p<.01)$, managing others' emotions $(r=.098, p<.05)$, and utilization of emotion $(r=.142, p<.01)$ have significant positive relationship with job satisfaction.

To answering research question 2, Multiple linear regression analysis has been used.

TABLE II

MULTICOLLINEARITY WITH TOLERANCE AND VIF MEASURES

\begin{tabular}{lccc}
\hline \multicolumn{1}{c}{ Variables } & \multicolumn{2}{c}{ Collinearity Statistic } & $\begin{array}{c}\text { Evidence of } \\
\text { Multicollinearity }\end{array}$ \\
\cline { 2 - 3 } & Tolerance & VIF & \\
\hline $\begin{array}{l}\text { Emotional } \\
\text { Intelligence }\end{array}$ & & & \\
$\begin{array}{l}\text { Managing Own } \\
\text { Emotions }\end{array}$ & .330 & 3.026 & No evidence \\
$\begin{array}{l}\text { Managing Others } \\
\text { Emotions }\end{array}$ & .434 & 2.276 & No evidence \\
Utilization of & .528 & 1.895 & No evidence \\
Emotion & & & \\
$\begin{array}{l}\text { Perception of } \\
\text { Emotion }\end{array}$ & .478 & 2.092 & No evidence \\
$\begin{array}{l}\text { Big Five Personality } \\
\text { Factors }\end{array}$ & & & \\
Conscientiousness & .550 & 1.819 & No evidence \\
$\begin{array}{l}\text { Agreeableness } \\
\text { Openness }\end{array}$ & .648 & 1.543 & No evidence \\
Neuroticism & .688 & 1.454 & No evidence \\
\hline
\end{tabular}

In reference to Table II, the tolerance of variables was between 0.330 to 0.688 , and the amount of VIF ranged from 1.454 to 3.026. Based on these results there is no multicollinearity among variables.

Table III reveals all the independent variables in the equation explained $(7 \%)$ of the variance. The study was used the enter method for analyzing multiple linear regression. The findings illustrated neuroticism and utilization of emotion are a significant proportion of variance in job satisfaction scores $\left(R^{2}=0.07, F(8,431)=3.916, p<.01\right)$. Utilization of emotion $(\beta$ $=.19, t(431)=2.96, p<.01)$, and neuroticism $(\beta=-.21, t(431)$ $=-3.74, p<.01)$ significantly predicted job satisfaction. 
TABLE III

MULTIPLE LINEAR REGRESSION ANALYSIS

\begin{tabular}{|c|c|c|c|c|c|}
\hline Variable & $\mathbf{B}$ & SE & $\boldsymbol{\beta}$ & $\mathbf{t}$ & $p$ \\
\hline Constant & 90.137 & 5.338 & & 16.885 & .000 \\
\hline \multicolumn{6}{|l|}{ Emotional Intelligence } \\
\hline Managing Own Emotions & -1.505 & 1.356 & -.090 & -1.109 & .268 \\
\hline Managing Others' & -.637 & 1.193 & -.037 & -.534 & .594 \\
\hline \multicolumn{6}{|l|}{ Emotions } \\
\hline Utilization of Emotion & 2.937 & .992 & .190 & 2.961 & $.003 * *$ \\
\hline Perception of Emotion & .686 & 1.184 & .039 & .580 & .563 \\
\hline \multicolumn{6}{|l|}{$\begin{array}{l}\text { Big Five Personality } \\
\text { factors }\end{array}$} \\
\hline Conscientiousness & -.214 & .850 & -.016 & -.252 & .802 \\
\hline Agreeableness & .307 & .897 & .020 & .342 & .732 \\
\hline Neuroticism & -2.270 & .606 & -.216 & -3.744 & $.000 * *$ \\
\hline Openness & .390 & .752 & .029 & .518 & .604 \\
\hline
\end{tabular}

Note: $F(8,431)=3.916, * * p<.01, R=.26, R^{2}=.07$, Adjusted $R^{2=} .050$

To answering research question 3, Mediating Test has been used.

Table IV shows the direct effect of neuroticism on job satisfaction ( $c$ path) is significant $(b=-2.270, p<0.01)$. Also, the direct effect of neuroticism on perception of emotion ( $a$ path) is significant $(\mathrm{b}=-.166, p<0.01)$. Conversely, the relationship between perception of emotion and job satisfaction ( $b$ path) is not significant $(b=0.686, p=0.563)$. Thus, the perception of emotion does not mediate the relationship between neuroticism and job satisfaction. The Sobel test calculation also showed that the indirect effect of neuroticism on job satisfaction is statistically insignificant $(z=.575, p=.565)$.

Table $\mathrm{V}$ displays that the direct effect of neuroticism on job satisfaction ( $c$ path) is significant $(\mathrm{b}=-2.270, p<0.01)$. As well, the direct effect of neuroticism on managing own emotions ( $a$ path) is significant $(b=-.293, p<0.01)$. In contrast, the relationship between managing own emotions and job satisfaction ( $b$ path) is not significant $(\mathrm{b}=$ $1.505, p=.268)$. Therefore, managing own emotions does not mediate the relationship between neuroticism and job satisfaction. The Sobel test calculation further illustrated that the indirect effect of neuroticism on job satisfaction is statistically insignificant $(z=1.102, p=.270)$.

TABLE IV

MEDIATING TEST OF NEUROTICISM ON JOB SATISFACTION THROUGH PERCEPTION OF EMOTION

\begin{tabular}{llccccc}
\hline \multicolumn{1}{c}{ IV } & \multicolumn{1}{c}{ DV } & B & SE & $\boldsymbol{\beta}$ & $\mathbf{t}$ & $\boldsymbol{p}$ \\
\hline Neuroticism & Job Satisfaction & -2.270 & .606 & -.216 & -3.744 & $.000 * *$ \\
Neuroticism & Perception of Emotion & -.166 & .035 & -.222 & -4.776 & $.000 * *$ \\
Perception of Emotion & Job Satisfaction & .686 & 1.184 & .039 & .580 & .563 \\
\hline Note: B=Unstandardized Coefficient; Beta=Standardized Coefficient; $* * p<.01, * p<.05$ &
\end{tabular}

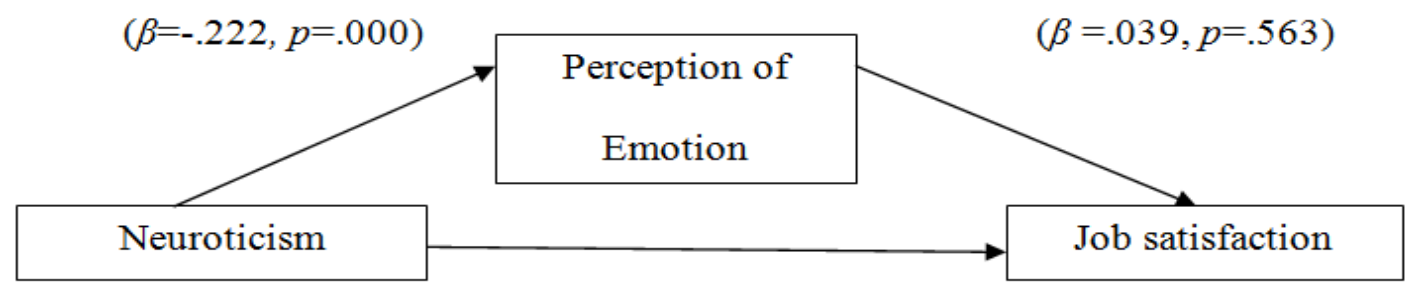

$$
(\beta=-.216, p=.000)
$$

Fig. 1 The Mediating Role of Perception of Emotion on the Relationship between Neuroticism and Job Satisfaction

TABLE V

MEDiATING TEST OF NEUROTICISM ON JOB SATISFACTION THROUGH MANAGING OWN EMOTIONS

\begin{tabular}{llccccc}
\hline \multicolumn{1}{c}{ IV } & \multicolumn{1}{c}{ DV } & B & SE & $\boldsymbol{\beta}$ & t & $\boldsymbol{p}$ \\
\hline Neuroticism & Job Satisfaction & -2.270 & .606 & -.216 & -3.744 & $.000^{* *}$ \\
Neuroticism & Managing Own Emotions & -.293 & .031 & -.416 & -9.561 & $.000^{* *}$ \\
Managing Own Emotions & Job Satisfaction & -1.505 & 1.356 & -.090 & -1.109 & .268 \\
\hline
\end{tabular}

Note: $\mathrm{B}=$ Unstandardized Coefficient; Beta=Standardized Coefficient; $* * p<.01, * p<.05$ 


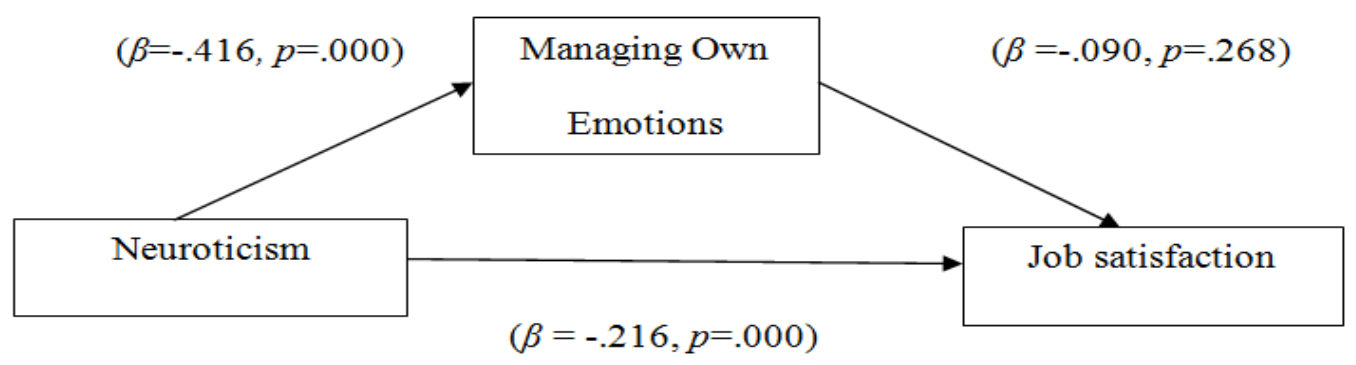

Fig. 2 The Mediating Role of Managing Own Emotions on the Relationship between Neuroticism and Job Satisfaction

Table VI displays that the direct effect of neuroticism on job satisfaction ( $c$ path) is significant $(\mathrm{b}=-2.270, p<0.01)$. Likewise, the direct effect of neuroticism on managing others' emotions ( $a$ path) is significant $(b=-.140, p<0.01)$. On the other hand, the relationship between managing others' emotions and job satisfaction ( $b$ path) is not significant $(b=$ $.637, p=.594)$. Thus, managing others' emotions does not mediate the relationship between neuroticism and job satisfaction. The Sobel test calculation similarly showed that the indirect effect of neuroticism on job satisfaction is statistically insignificant $(z=.530, p=.595)$.
Table VII shows the direct effect of agreeableness on job satisfaction ( $c$ path) is not significant $(\mathrm{b}=.307, p=.732)$; additionally, the relationship between perception of emotion and job satisfaction ( $b$ path) is not significant $(b=0.686, p$ $=.563)$. On the other hand, the direct effect of agreeableness on perception of emotion ( $a$ path) is significant $(b=.366, p<$ 0.01). Thus, the perception of emotion does not mediate the relationship between agreeableness and job satisfaction. The calculation of the Sobel test also showed that the indirect effect of agreeableness on job satisfaction is statistically insignificant $(z=.036, p=.971)$.

TABLE VI

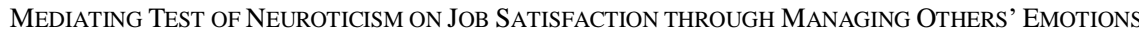

\begin{tabular}{llccccc}
\hline \multicolumn{1}{c}{ IV } & \multicolumn{1}{c}{ DV } & B & SE & $\boldsymbol{\beta}$ & t & $\boldsymbol{p}$ \\
\hline Neuroticism & Job Satisfaction & -2.270 & .606 & -.216 & -3.744 & $.000 * *$ \\
Neuroticism & Managing Others' Emotions & -.140 & .029 & -.227 & -4.889 & $.000 * *$ \\
Managing Others' Emotions & Job Satisfaction & -.637 & 1.193 & -.037 & -.534 & .594 \\
\hline
\end{tabular}

Note: B=Unstandardized Coefficient; Beta=Standardized Coefficient; $* * p<.01,{ }^{*} p<.05$

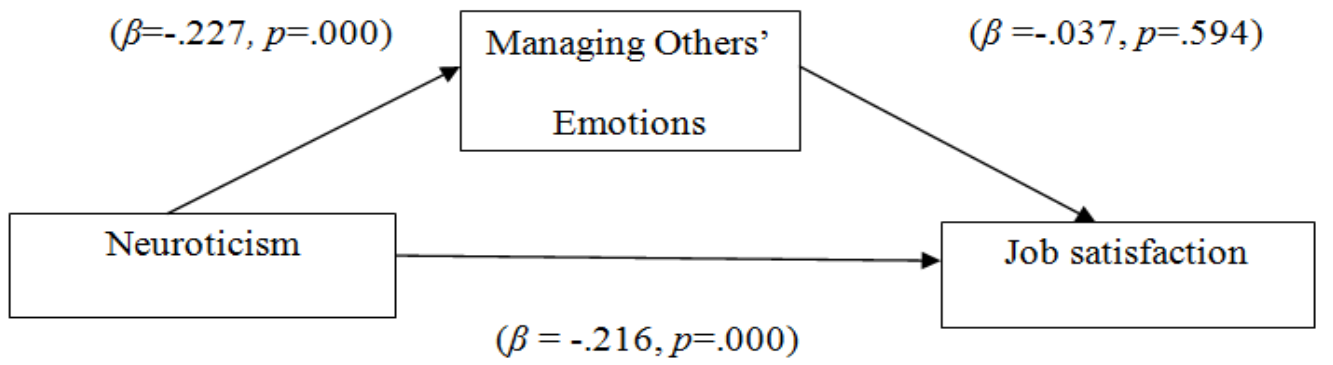

Fig. 3 The Mediating Role of Managing Others' Emotions on the Relationship between Neuroticism and Job Satisfaction

TABLE VII

MEdiating TEST OF AGREEABLENESS ON JOB SATISFACTION THROUGH PERCEPTION OF EMOTION

\begin{tabular}{llccccc}
\hline \multicolumn{1}{c}{ IV } & \multicolumn{1}{c}{ DV } & B & SE & $\boldsymbol{\beta}$ & t & $\boldsymbol{p}$ \\
\hline Agreeableness & Job Satisfaction & .307 & .897 & .020 & .342 & .732 \\
Agreeableness & Perception of Emotion & .366 & .043 & .373 & 8.413 & $.000 * *$ \\
Perception of Emotion & Job Satisfaction & .686 & 1.184 & .039 & .580 & .563 \\
\hline Note: B=Unstandardized Coefficient; Beta=Standardized Coefficient; $* * p<.01, * p<.05$ &
\end{tabular}




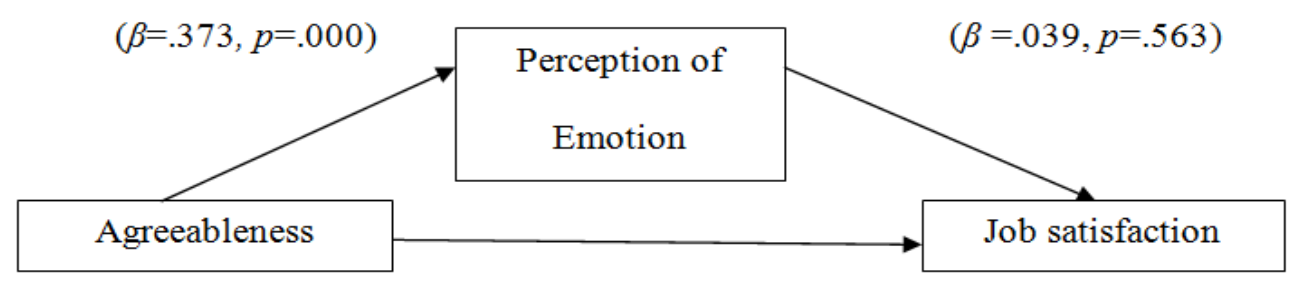

$$
(\beta=.020, p=.732)
$$

Fig. 4 The Mediating Role of Perception of Emotion on the Relationship between Agreeableness and Job Satisfaction

Table VIII displays the direct effect of agreeableness on job satisfaction ( $c$ path) is not significant $(\mathrm{b}=.307, p=.732)$; also, the relationship between managing own emotions and job satisfaction ( $b$ path) is not significant $(\mathrm{b}=-1.505, p=.268)$. Conversely, the direct effect of agreeableness on managing own emotions ( $a$ path) is significant $(b=.421, p<0.01)$. So, managing own emotions does not mediate the relationship between agreeableness and job satisfaction. Likewise, the Sobel test calculation presented that the indirect effect of agreeableness on job satisfaction is statistically insignificant $(z=.028, p=.977)$.
Table IX demonstrates that the direct effect of agreeableness on job satisfaction ( $c$ path) is not significant (b $=.307, p=.732)$; similarly, the relationship between managing others' emotions and job satisfaction ( $b$ path) is not significant ( $b=-.637, p=.594)$. Conversely, the direct effect of agreeableness on managing others' emotions ( $a$ path) is significant $(\mathrm{b}=.353, p<0.01)$. Consequently, managing others' emotions does not mediate the relationship between agreeableness and job satisfaction. The Sobel test calculation further illustrated that the indirect effect of agreeableness on job satisfaction is statistically insignificant $(z=.533, p=.593)$.

TABLE VIII

Mediating TEST of AgreEABLENESS ON JOB SATISFACTION THROUGH MANAGING OWN EMOTIONS

\begin{tabular}{llccccc}
\hline \multicolumn{1}{c}{ IV } & \multicolumn{1}{c}{ DV } & B & SE & $\boldsymbol{\beta}$ & t & $\boldsymbol{p}$ \\
\hline Agreeableness & Job Satisfaction & .307 & .897 & .020 & .342 & .732 \\
Agreeableness & Managing Own Emotions & .421 & .039 & .454 & 10.699 & $.000^{* *}$ \\
Managing Own Emotions & Job Satisfaction & -1.505 & 1.356 & -.090 & -1.109 & .268 \\
\hline Note: B=Unstandardized Coefficient; Beta=Standardized Coefficient; $* * p<.01, p<.05$ & &
\end{tabular}

Note: $\mathrm{B}=$ Unstandardized Coefficient; Beta=Standardized Coefficient; $* * p<.01, * p<.05$

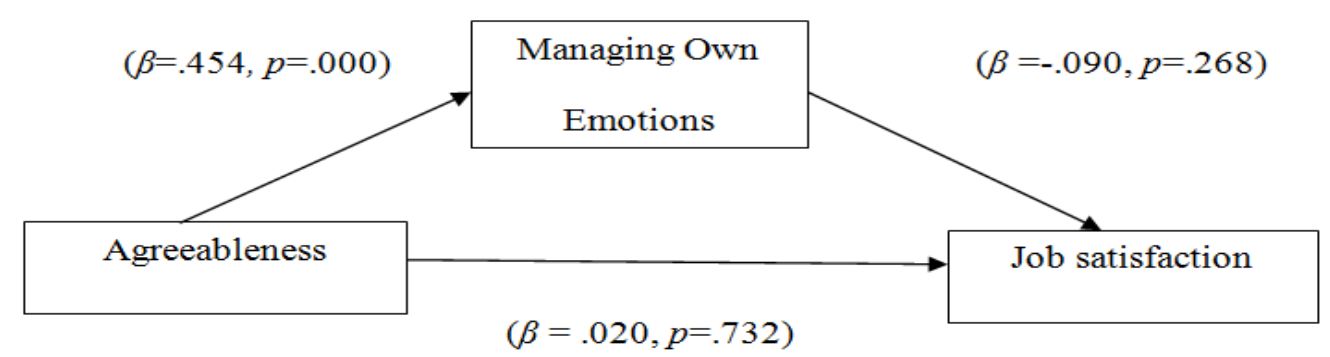

Fig. 5 The Mediating Role of Managing Own Emotions on the Relationship between Agreeableness and Job Satisfaction

TABLE IX

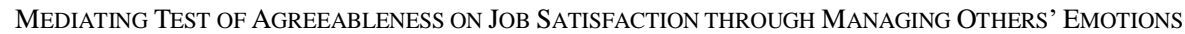

\begin{tabular}{|c|c|c|c|c|c|c|}
\hline IV & DV & B & SE & $\beta$ & $\mathbf{t}$ & $p$ \\
\hline Agreeableness & Job Satisfaction & .307 & .897 & .020 & .342 & .732 \\
\hline Agreeableness & Managing Other's Emotions & .353 & .035 & .435 & 10.098 & $.000 * *$ \\
\hline Managing Other's Emotions & Job Satisfaction & -.637 & 1.193 & -.037 & -.534 & .594 \\
\hline
\end{tabular}




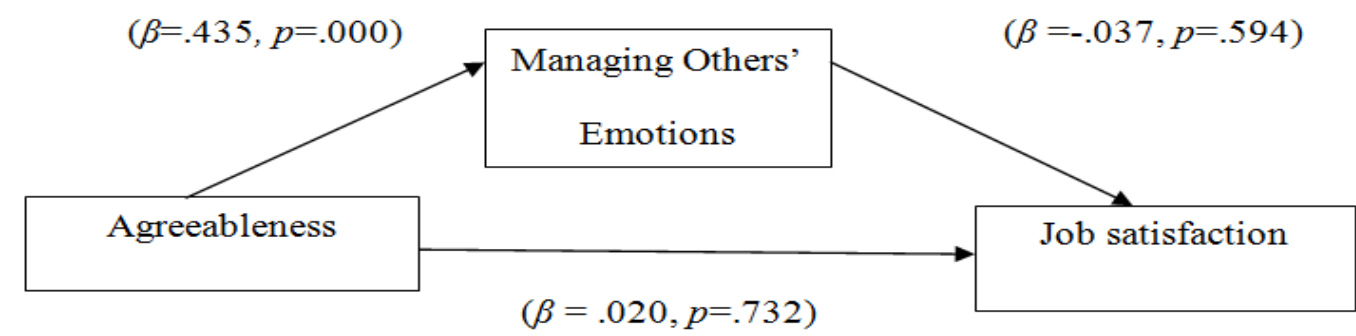

Fig. 6 The Mediating Role of Managing Others' Emotions on the Relationship between Agreeableness and Job Satisfaction

Table $\mathrm{X}$ shows that the direct effect of agreeableness on job satisfaction ( $c$ path) is not significant $(\mathrm{b}=.307, p=.732)$. In contrast, the direct effect of agreeableness on utilization of emotion ( $a$ path) is significant $(\mathrm{b}=.199, p<0.01)$. Also, the relationship between utilization of emotion and job satisfaction ( $b$ path) is significant $(\mathrm{b}=2.937, p=.003)$. Thus, the utilization of emotion fully mediates the relationship between agreeableness and job satisfaction. The Sobel test calculation also illustrated that the indirect effect of agreeableness on job satisfaction is statistically significant $(z=$ $2.703, p=.006)$.
Table XI shows that the direct effect of conscientiousness on job satisfaction (ć path) is not significant $(b=$ $.214, p=.802)$. Conversely, the direct effect of conscientiousness on perception of emotion ( $a$ path) is significant $(b=.355, p<0.01)$. Finally, the relationship between perception of emotion and job satisfaction ( $b$ path) is not significant $(\mathrm{b}=0.686, p=.563)$. Thus, the perception of emotion does not mediate the relationship between conscientiousness and job satisfaction. The Sobel test calculation also showed that the indirect effect of conscientiousness on job satisfaction is statistically insignificant $(\mathrm{z}=.578, p=.563)$.

TABLE X

MEDiATING TEST OF AgREEABLENESS ON JOB SATISFACTION THROUGH UTILIZATION OF EMOTION

\begin{tabular}{llccccc}
\hline \multicolumn{1}{c}{ IV } & \multicolumn{1}{c}{ DV } & B & SE & $\boldsymbol{\beta}$ & $\mathbf{t}$ & $\boldsymbol{p}$ \\
\hline Agreeableness & Job Satisfaction & .307 & .897 & .020 & .342 & .732 \\
Agreeableness & Utilization of Emotion & .199 & .030 & .298 & 6.530 & $.000^{* *}$ \\
Utilization of Emotion & Job Satisfaction & 2.937 & .992 & .190 & 2.961 & .003 \\
\hline
\end{tabular}

Note: $\mathrm{B}=$ Unstandardized Coefficient; Beta=Standardized Coefficient; $* * p<.01, * p<.05$

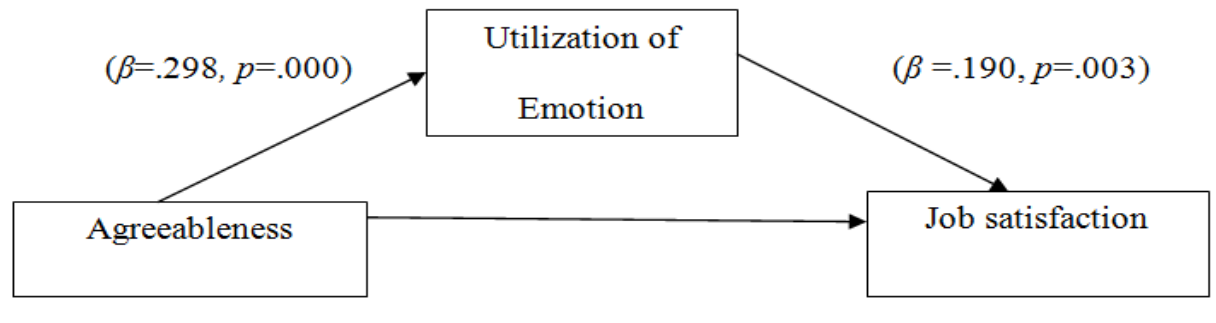

$(\beta=.020, p=.732)$

Fig. 7 The Mediating Role of Utilization of Emotion on the Relationship between Agreeableness and Job Satisfaction

TABLE XI

MEdiating Test OF CONSCIENTIOUSNESS ON Job SATISFACTION THROUgh PERCEPTION OF EMOTION

\begin{tabular}{llccccc}
\hline \multicolumn{1}{c}{ IV } & \multicolumn{1}{c}{ DV } & B & SE & $\boldsymbol{\beta}$ & t & $\boldsymbol{p}$ \\
\hline Conscientiousness & Job Satisfaction & -.214 & .850 & -.016 & -.252 & .802 \\
Conscientiousness & Perception of Emotion & .355 & .038 & .391 & 8.902 & $.000^{* *}$ \\
Perception of Emotion & Job Satisfaction & .686 & 1.184 & .039 & .580 & .563 \\
\hline Note: B=Unstandardized Coefficient; Beta=Standardized Coefficient; ** $p<.01, * p<.05$ &
\end{tabular}




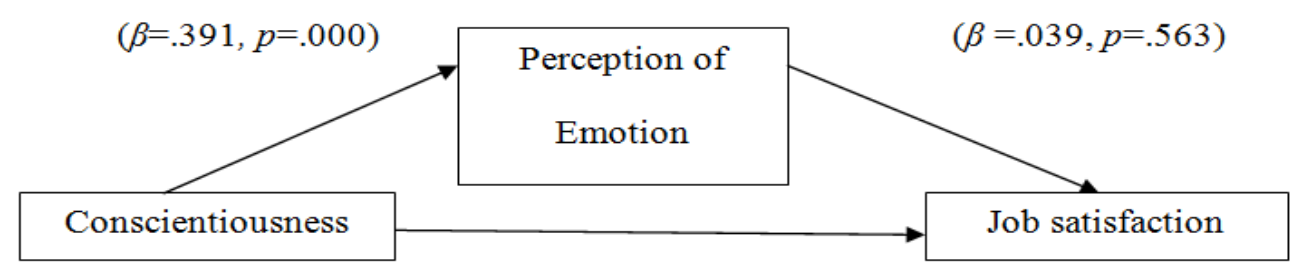

$$
(\beta=-.016, p=.802)
$$

Fig. 8 The Mediating Role of Perception of Emotion on the Relationship between Conscientiousness and Job Satisfaction

Table XII demonstrates the direct effect of conscientiousness on job satisfaction ( $c$ path) is not significant $(\mathrm{b}=-.214, p=.802)$; while the direct effect of conscientiousness on managing own emotion ( $a$ path) is significant $(b=.411, p<0.01)$. Finally, the relationship between managing own emotion and job satisfaction ( $b$ path) is not significant $(\mathrm{b}=-1.505, p=.268)$. Thus, managing own emotions does not mediate the relationship between conscientiousness and job satisfaction. The Sobel test calculation further illustrated that the indirect effect of conscientiousness on job satisfaction is statistically insignificant $(z=1.105, p=.268)$.
Table XIII shows that the direct effect of conscientiousness on job satisfaction ( $c$ path) is not significant (b = $.214, p=.802)$. On the other hand, the direct impact of conscientiousness on managing others' emotions ( $a$ path) is significant $(b=.308, p<0.01)$. Finally, the relationship between managing others' emotions and job satisfaction ( $b$ path) is not significant $(\mathrm{b}=-.637, p=.594)$. Therefore, managing others' emotions does not mediate the relationship between conscientiousness and job satisfaction. The Sobel test calculation also illustrated that the indirect effect of conscientiousness on job satisfaction is statistically insignificant $(z=.533, p=.593)$.

TABLE XII

MEdiating TEST OF CONSCIENTIOUSNESS ON Job SATISFACTION THROUGH MANAGING OWN EMOTIONS

\begin{tabular}{llccccc}
\hline \multicolumn{1}{c}{ IV } & \multicolumn{1}{c}{ DV } & B & SE & $\boldsymbol{\beta}$ & t & $\boldsymbol{p}$ \\
\hline Conscientiousness & Job Satisfaction & -.214 & .850 & -.016 & -.252 & .802 \\
Conscientiousness & Managing Own Emotions & .411 & .033 & .508 & 12.349 & $.000 * *$ \\
Managing Own Emotions & Job Satisfaction & -1.505 & 1.356 & -.090 & -1.109 & .268 \\
\hline Note: B=Unstandardized Coefficient; Beta=Standardized Coefficient; $* * p<.01, * p<.05$ & &
\end{tabular}

Note: $\mathrm{B}=$ Unstandardized Coefficient; Beta=Standardized Coefficient; $* * p<.01, * p<.05$

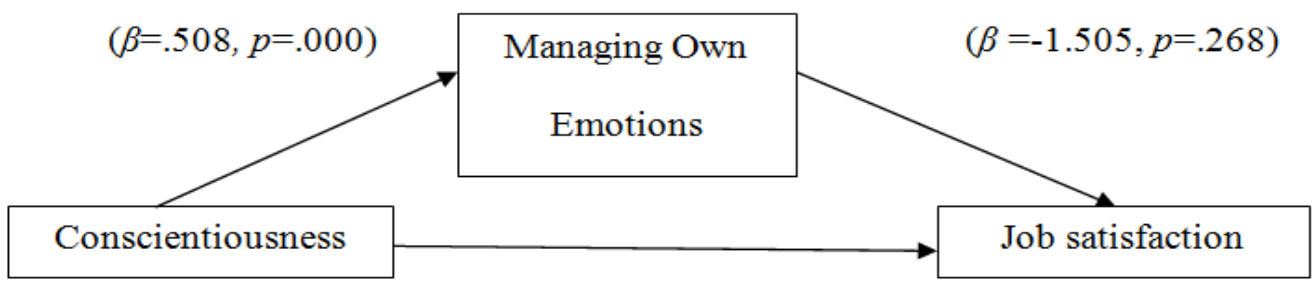

$$
(\beta=-.016, p=.802)
$$

Fig. 9 The Mediating Role of Managing Own Emotions on the Relationship between Conscientiousness and Job Satisfaction

TABLE XIII

MEDiATING TEST OF CONSCIENTIOUSNESS ON JOB SATISFACTION THROUGH MANAGING OTHERS' EMOTIONS

\begin{tabular}{llccccc}
\hline \multicolumn{1}{c}{ IV } & \multicolumn{1}{c}{ DV } & B & SE & $\boldsymbol{\beta}$ & t & $\boldsymbol{p}$ \\
\hline Conscientiousness & Job Satisfaction & -.214 & .850 & -.016 & -.252 & .802 \\
Conscientiousness & Managing Others' Emotions & .308 & .030 & .434 & 10.091 & $.000 * *$ \\
Managing Others' Emotions & Job Satisfaction & -.637 & 1.193 & -.037 & -.534 & .594 \\
\hline Note: B=Unstandardized Coefficient; Beta=Standardized Coefficient; $* * p<.01, * p<.05$ & &
\end{tabular}




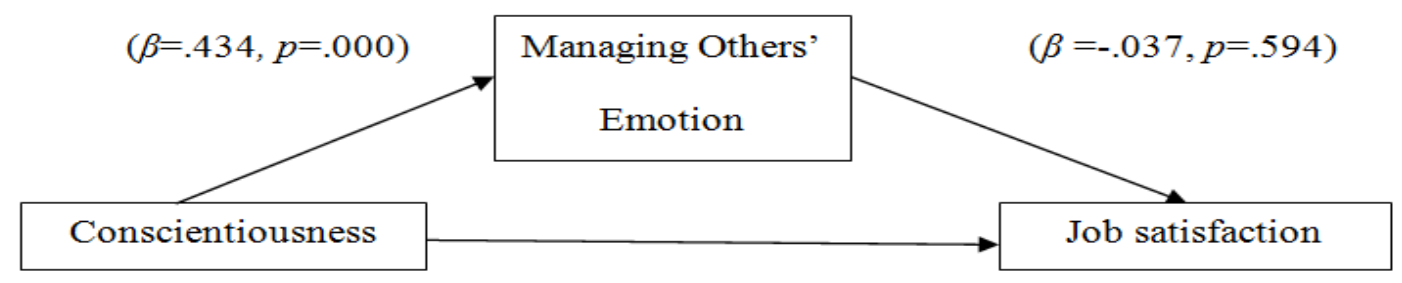

$$
(\beta=-.016, p=.802)
$$

Fig. 10 The Mediating Role of Managing Others' Emotion on the Relationship between Conscientiousness and Job Satisfaction

Table XIV displays that the direct effect of conscientiousness on job satisfaction ( $\dot{c}$ path) is not significant ( $\mathrm{b}=-.214, p=.802)$. Conversely, the direct effect of conscientiousness on utilization of emotion ( $a$ path) is significant $(b=.169, p<0.01)$. Additionally, the relationship between utilization of emotion and job satisfaction ( $b$ path) is significant $(b=2.937, p=.003)$. Thus, the utilization of emotion fully mediates the relationship between conscientiousness and job satisfaction. The Sobel test calculation also illustrated that the indirect effect of conscientiousness on job satisfaction is statistically significant $(z=2.676, p=.007)$.
Table XV shows that the direct effect of openness on job satisfaction ( $c$ path) is not significant $(b=.390, p=.604)$; while the direct effect of openness on perception of emotion ( $a$ path) is significant $(\mathrm{b}=.372, p<0.01)$. Finally, the relationship between perception of emotion and job satisfaction ( $b$ path) is not significant $(b=0.686, p=.563)$. Thus, the perception of emotion does not mediate the relationship between openness and job satisfaction. Likewise, the Sobel test calculation showed that the indirect effect of openness on job satisfaction is statistically insignificant $(z=.578, p=.562)$.

TABLE XIV

MEDIATING TEST OF CONSCIENTIOUSNESS ON JOB SATISFACTION THROUGH UTILIZATION OF EMOTION

\begin{tabular}{llccccc}
\hline \multicolumn{1}{c}{ IV } & \multicolumn{1}{c}{ DV } & B & SE & $\boldsymbol{\beta}$ & t & $\boldsymbol{p}$ \\
\hline Conscientiousness & Job Satisfaction & -.214 & .850 & -.016 & -.252 & .802 \\
Conscientiousness & Utilization of Emotion & .169 & .027 & .289 & 6.328 & $.000^{* *}$ \\
Utilization of Emotion & Job Satisfaction & 2.937 & .992 & .190 & 2.961 & .003 \\
\hline
\end{tabular}

Note: $\mathrm{B}=$ Unstandardized Coefficient; Beta=Standardized Coefficient; $* * p<.01,{ }^{*} p<.05$

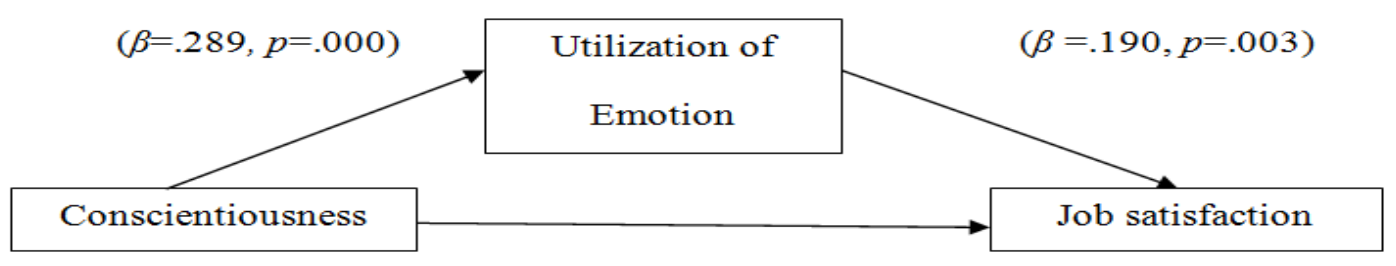

$$
(\beta=-.016, p=.802)
$$

Fig. 11 The Mediating Role of Utilization of Emotion on the Relationship between Conscientiousness and Job Satisfaction

TABLE XV

MEDIATING TEST OF OPENNESS ON JOB SATISFACTION THROUGH PERCEPTION OF EMOTION

\begin{tabular}{lllllll}
\hline \multicolumn{1}{c}{ IV } & \multicolumn{1}{c}{ DV } & B & SE & $\boldsymbol{\beta}$ & t & $\boldsymbol{p}$ \\
\hline Openness & Job Satisfaction & .390 & .752 & .029 & .518 & .604 \\
Openness & Perception of Emotion & .372 & .033 & .429 & 9.932 & $.000^{* *}$ \\
Perception of Emotion & Job Satisfaction & .686 & 1.184 & .039 & .580 & .563 \\
\hline Note: B=Unstandardized Coefficient; Beta-Standardized Cofficient;
\end{tabular}

Note: $\mathrm{B}=$ Unstandardized Coefficient; Beta=Standardized Coefficient; $* * p<.01, * p<.05$ 


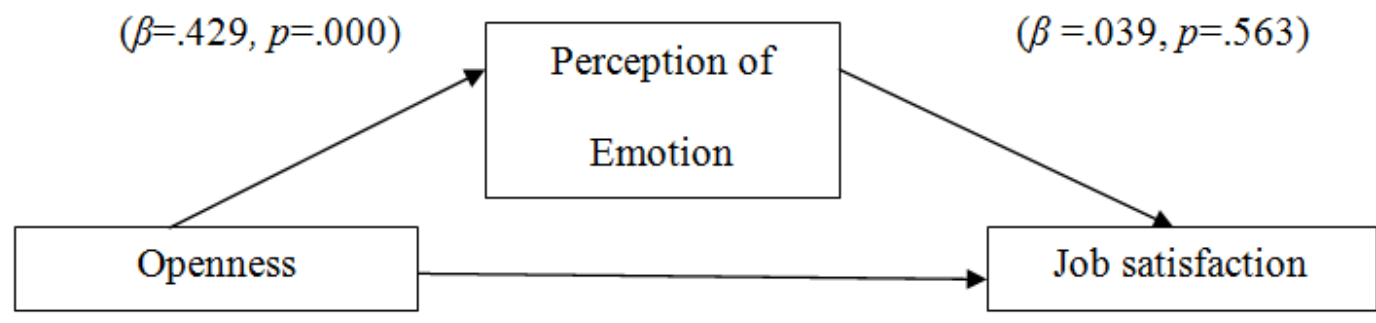

$$
(\beta=.029, p=.604)
$$

Fig. 12 The Mediating Role of Perception of Emotion on the Relationship between Openness and Job Satisfaction

Table XVI illustrates that the direct effect of openness on job satisfaction ( $c$ path) is not significant $(\mathrm{b}=.390, p=.604)$. In contrast, the direct effect of openness on managing own emotions ( $a$ path) is significant $(b=.350, p<0.01)$. Finally, the relationship between managing own emotions and job satisfaction ( $b$ path) is not significant $(\mathrm{b}=-1.505, p=.268)$. Thus, managing own emotions does not mediate the relationship between openness and job satisfaction. The Sobel test calculation also showed that the indirect effect of openness on job satisfaction is statistically insignificant $(z=$ $1.104, p=.269)$.

Table XVII displays that the direct effect of openness on job satisfaction ( $c$ path) is not significant $(b=.390, \mathrm{p}=.604)$. On the other hand, the direct effect of openness on managing others' emotions ( $a$ path) is significant $(b=.252, p<0.01)$. Finally, the relationship between managing others' emotions and job satisfaction ( $b$ path) is not significant $(b=-.637, p$ $=.594)$. Thus, managing others' emotions does not mediate the relationship between openness and job satisfaction. The Sobel test calculation also showed that the indirect effect of openness on job satisfaction is statistically insignificant $(\mathrm{z}$ $=.533, p=.594)$.

Table XVIII demonstrates the direct effect of openness on job satisfaction ( $c$ path) is not significant $(b=.390, p=.604)$. Conversely, the direct effect of openness on utilization of emotion ( $a$ path) is significant $(\mathrm{b}=.191, p<0.01)$; additionally, the relationship between utilization of emotion and job satisfaction ( $b$ path) is significant $(b=2.937, p=.003)$. Thus, the utilization of emotion fully mediates the relationship between openness and job satisfaction. Similarly, the Sobel test calculation revealed that the indirect effect of openness on job satisfaction is statistically significant $(z=2.788, p=.005)$.

TABLE XVI

MEDiATING TeSt OF OPENNESS ON Job SATISFACTION THROUGH MANAGING OWN EMOTIONS

\begin{tabular}{llccccc}
\hline \multicolumn{1}{c}{ IV } & \multicolumn{1}{c}{ DV } & B & SE & $\boldsymbol{\beta}$ & t & $\boldsymbol{p}$ \\
\hline Openness & Job Satisfaction & .390 & .752 & .029 & .518 & .604 \\
Openness & Managing Own Emotions & .350 & .030 & .486 & 11.651 & $.000^{* *}$ \\
Managing Own Emotions & Job Satisfaction & -1.505 & 1.356 & -.090 & -1.109 & .268 \\
\hline
\end{tabular}

Note: $\mathrm{B}=$ Unstandardized Coefficient; Beta=Standardized Coefficient; $* * p<.01, * p<.05$

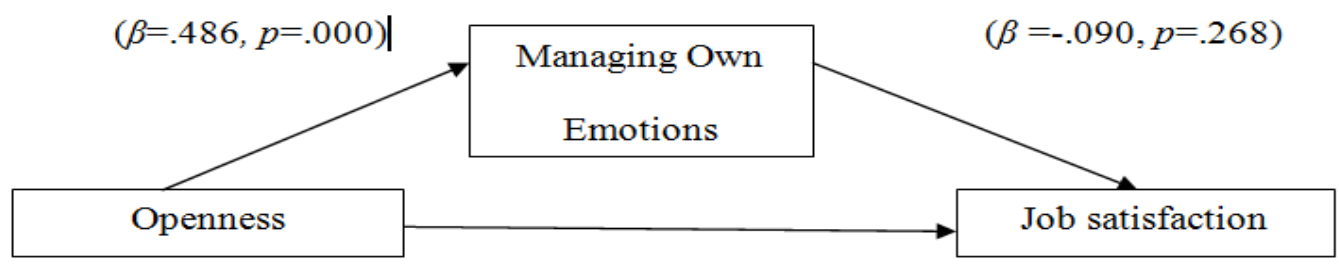

$$
(\beta=.029, p=.604)
$$

Fig. 13 The Mediating Role of Managing Own Emotions on the Relationship between Openness and Job Satisfaction

TABLE XVII

MEDiATING TEST OF OPENNESS ON JOB SATISFACTION THROUGH MANAGING OTHERS' EMOTIONS

\begin{tabular}{lllcccc}
\hline \multicolumn{1}{c}{ IV } & \multicolumn{1}{c}{ DV } & B & SE & $\boldsymbol{\beta}$ & t & $\boldsymbol{p}$ \\
\hline Openness & Job Satisfaction & .390 & .752 & .029 & .518 & .604 \\
Openness & Managing Others' Emotions & .252 & .028 & .399 & 9.110 & $.000 * *$ \\
Managing Others' Emotions & Job Satisfaction & -.637 & 1.193 & -.037 & -.534 & .594 \\
\hline
\end{tabular}

Note: $\mathrm{B}=$ Unstandardized Coefficient; Beta=Standardized Coefficient; $* * p<.01, * p<.05$ 


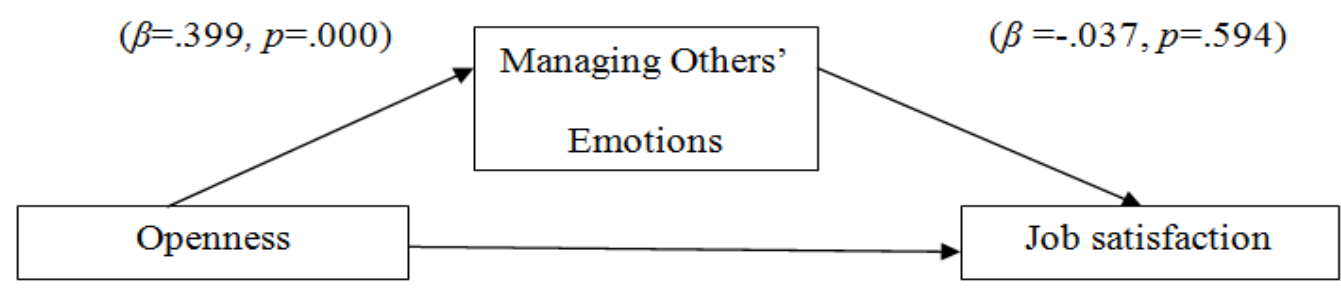

$$
(\beta=.029, p=.604)
$$

Fig. 14 The Mediating Role of Managing Others' Emotions on the Relationship between Openness and Job Satisfaction

TABLE XVIII

MEDIATING TEST OF OPENNESS ON JOB SATISFACTION THROUGH UTILIZATION OF EMOTION

\begin{tabular}{lllllll}
\hline \multicolumn{1}{c}{ IV } & \multicolumn{1}{c}{ DV } & B & SE & $\boldsymbol{\beta}$ & t & $\boldsymbol{p}$ \\
\hline Openness & Job Satisfaction & .390 & .752 & .029 & .518 & .604 \\
Openness & Utilization of Emotion & .191 & .023 & .368 & 8.286 & $.000^{* *}$ \\
Utilization of Emotion & Job Satisfaction & 2.937 & .992 & .190 & 2.961 & .003 \\
\hline
\end{tabular}

Note: $\mathrm{B}=$ Unstandardized Coefficient; Beta=Standardized Coefficient; $* * p<.01, * p<.05$

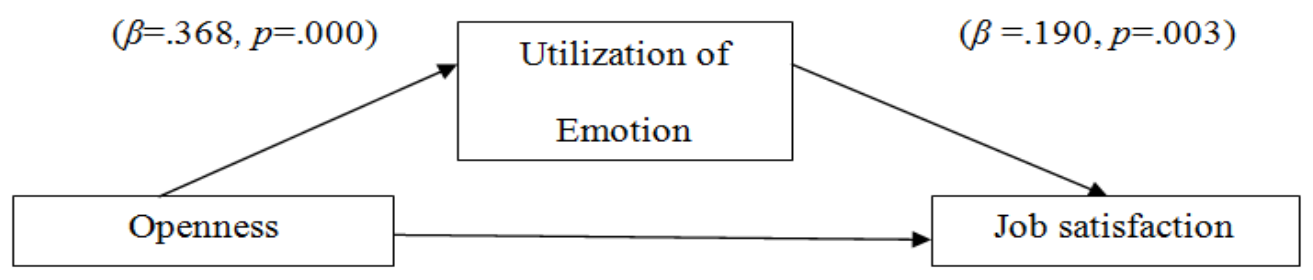

$$
(\beta=.029, p=.604)
$$

Fig. 15 The Mediating Role of Utilization of Emotion on the Relationship between Openness and Job Satisfaction

\section{B. Discussion}

According to the aim of this study, which focused on the relationship of big five personality factors and job satisfaction with the mediatory role of emotional intelligence; the findings are following the results of earlier studies (Furnham \& Christoforou, 2007; Hazrati, Zabihi, \& Mehdizadeh, 2013) which suggested that factors of personality have a powerful effect on the variation of emotional intelligence and this effect illustrates the close relationship between these variables. It was also consistent with prior research done by Nawi et al. (2015), who argued that personality factors among university staff have a fundamental role in their organizational reactions and predict the amount of their emotional intelligence. Similarly, Chen and Lai (2015) focused on staff personality and emotions in Malaysian universities. The researchers reported that extraversion, agreeableness, conscientiousness, and openness have positive relationships with staff emotional intelligence, and the increase of their emotional intelligence leads to these factors. Conversely, neuroticism has an adverse association with emotional intelligence, and an increase in staff emotional intelligence leads to a decrease in this factor.
In earlier studies, it is explained that there are significant associations between all factors of personality with emotional intelligence. In contrast, in the present study, it is shown that there is no significant relationship between utilization of emotion and neuroticism. This study also disclosed that conscientiousness, openness, and agreeableness yielded positive, meaningful relationships with job satisfaction, while neuroticism has an adverse correlation with job satisfaction. These findings are by the results of Ayan and Kocacik (2010), Bockhaus et al. (2012), Therasa and Vijayabanu (2012), who noted that personality factors have a considerable role on job satisfaction and impact individuals' view toward their job. It is likewise consistent with previous studies done by Fayombo (2010), Naz et al. (2013), Ganu and Kogutu (2014), Ijaz and Khan (2015), who suggested that there is an adverse relationship between neuroticism and job satisfaction. Conversely, there are positive associations between job satisfaction and conscientiousness, openness, extraversion, and agreeableness. As well, the findings of this study support previous investigation done by Yahaya et al. (2012) in the Malaysian workplace; the researchers argued that openness, agreeableness, extraversion, and conscientiousness created 
confident reactions and behaviors such as likely to continue in the current position and avoid any absence or job cancellation amongst staff. Also, the findings of the study support earlier examinations are done by Alam (2009), Mousavi et al. (2012), and Coetzer (2013) who considered factors of emotional intelligence and reported that there is a significant relationship between perception, managing others' emotions, and utilization with job satisfaction.

It can conclude that the utilization of emotion and neuroticism amongst academic staff in public research universities in the Kelang Valley area has a considerable role in predicting job satisfaction. These findings agree with Alam (2009); and Ngah, Jusoff, and Abdul Rahman (2009), who explained utilization as one of the main factors of emotional intelligence significantly associated with job satisfaction. Likewise, the findings are like Tesdimir, Zaheer Asghar, and Saeed (2010), who concentrated on personality factors and explained that neuroticism predicts the level of job satisfaction.

The findings showed that utilization of emotion as one of the emotional intelligence factors was a mediator of the association between personality factors (agreeableness, conscientiousness, and openness) and academic staff's job satisfaction at public research universities in Klang Valley, Malaysia. These findings are consistent with $\mathrm{Ngah}$ et al. (2009) and Platsidou (2013) who explained that utilization of emotion has a considerable impact on staff's feelings and attitudes; additionally, this emotional intelligence factor is influenced by other elements of the work environment. However, through the present findings, there are some supports for associations between emotional intelligence and job satisfaction, making emotional intelligence (utilization of emotion) reasonable mediators between big five personality factors and job satisfaction. Furthermore, in the current study, utilization of emotion fully mediated the relationship between agreeableness, conscientiousness, and openness with academic staff's job satisfaction.

\section{CONCLUSIONS}

\section{A. Conclusions}

This study's outcomes indicate that five personality factors and emotional intelligence influence respondents' job satisfaction. The study applied various methods to discover relationships between variables, determine predictor variables, and the mediator variable's role in the relationships between dependent variables and the independent variables. Indeed, the findings indicated that various factors motivate academic staff job satisfaction and change their attitudes and beliefs toward their position at the university. This study's findings demonstrated conscientiousness, openness, and agreeableness have positive relationships with job satisfaction. The academic staff with these personalities show better reactions to the struggles of the workplace. At the same time, neuroticism decreases job satisfaction, and neurotic academic staff illustrates unusual and negative organizational behavior. Moreover, the university can get early information about new academic staff's personality by appropriate screening tests and determining some effectual strategies for the neurotic academic staff to restrict uncommon organizational behavior. Emotional intelligence factors also have a positive effect on job satisfaction and increase the level of job satisfaction. Academic staff who apply their emotional intelligence, or in other words, are motivated by emotions, have better feelings toward their job, and managing their affairs at the university. Additionally, conscientiousness, openness, extrovert, and agreeableness academic staff have more emotions than the neurotic academic staff. This study has found that generally, neuroticism and emotion utilization predict academic staff job satisfaction at the university. Studying job satisfaction by linking it to five personality factors and emotional intelligence is relevant to the context of an educational organization such as public research universities. The present study's findings have proven that different factors impact job satisfaction among academic staff at public research universities in Klang Valley, Malaysia. Therefore, it is concluded that job satisfaction is a dependent factor that changed its amount by affecting several factors, such as personality factors and emotional intelligence.

\section{B. Implications}

The present study provides some empirical evidence that determines the impact of psychological variables on job satisfaction of academic staff; also, it has various practical implications for the social community, organizations particularly educational organizations, MOHE, universities, psychologists, managers, employees, and academic staff. Considering the role of job satisfaction among academic staff, identifying factors contributing to job satisfaction is essential. Furthermore, the first and major implication is distinguishing the basic human needs that should be supported by academic staff and university. The present study found that personality factors and emotional intelligence have significant relationships with job satisfaction. Furthermore, this implies that the university can obtain initial and necessary information about new academic staff's personality by using proper screening tests to control and restrict uncommon organizational behavior and manage prevention courses related to neurotic academic staff. Likewise, the university should consider emotional intelligence and specific utilization of emotion as the imperative alignment for intervention and prevention to increase job satisfaction among academic staff. This study likewise implies that academic staff, by knowing their personality, endeavor to control and reduce negative factors that have an unsatisfactory role in emotions and feeling toward job and workplace. Furthermore, it suggests that staff should be trained and improve their knowledge to recognize their personality and emotions; consequently, they can monitor their reactions and attitudes toward their job. This study's findings revealed that academic staff conveys feelings toward a job through their emotions, based on their personality factors. As A Result, the findings help academic staff be aware of their emotions in their personal and social lives. An appropriate working condition can be provided according to each positive and negative factor and applying the positive personality factors and emotional intelligence factors. Applying these positive factors lead to worthy 
attitudes towards the job. Finally, the current study's findings could support all the staff that works in any educational organization and institutes. It could be like a guide in planning for staff at the university.

\section{Recommendation}

The present study used primary data collected by the researcher from academic staff, but it is just limited to crosssectional design and data collected at one time. Furthermore, it is recommended that the investigation in this area performs longitudinal design if time and finance are sufficient for the researcher. Secondly, this study only focused on public research universities in the Klang Valley area, while job satisfaction is vital among staff in any educational organization and university. Moreover, it is recommended that future studies consider all universities, such as private and public universities, and compare these two universities together. Subsequently, the study was among academic staff, and the non-academic staff was not mentioned. Likewise, it is suggested that future studies extend the population and focus on academic and non-academic staff and compare the level of job satisfaction with each of these groups together. Undoubtedly, the situations and types of their attitudes in each of these groups are different and show various reactions toward job satisfaction.

\section{REFERENCES}

Akintayo, D. I., \& Babalola, S. S. (2012). The impact of emotional intelligence on workers' behavior in industrial organizations. Journal of Human and Social Psychology, 4(2), 83-90. https://doi.org/10.19030/iber.v7i2.3220

Alam, M. M. (2009). The relationships between the emotional intelligence and job satisfaction: Empirical findings from higher education institution in Malaysia. Journal of Management and Social Science, 5(2), 124-139.

Altbach, G. P., Reisberg, L., \& Rumbly, E. L. (2009). Trends in Global Higher Education: Tracking an Academic Revolution. Paris: UNESCO.

Ashraf, M., Nawaz, A., Shaikh, O. A., \& Bhatti, S. R. (2014). Emotional intelligence and job satisfaction among employees of service sector in Pakistan. International Journal of Innovative Research and Development, 3(5), 205-214.

Ayan, S., \& Kocacik, F. (2010). The relation between the level of job satisfaction and types of personality in high school teachers. Australian Journal of Teacher Education, 35(1), 26-41. https://doi.org/10.14221/ajte.2010v35n1.4

Bockhaus, K., Hillyer, M., \& Peterson, K. (2012). The relationship between personality type and job satisfaction. Canadian Medical Association Journal, 136, 1-12.

Bond, T. S. (2013). The Influence of Job Satisfaction, Organizational Commitment, and Employee Engagement on Intent to Leave among Public School Teachers in South Louisiana. Doctoral dissertation.
United States: Luisian State University (Unpublished).

Brodke, M., Sliter, M., Balzer, W., Gillespie, J., Gillespie, M., Gopalkrishnan, P., et al. (2009). The job descriptive index and job in general: 2009 revision quick reference guide. Bowling Green, $\mathrm{OH}$ : Bowling Green State University.

Chen, Y. T., \& Lai, S. L. (2015). Personality traits, emotional intelligence and academic achievements of university students. American Journal of Applied Psychology, $3(1)$, $39-44$. https://doi.org/10.11648/j.ajap.s.2015040301.17

Coetzer, W. C. (2013). The Relationship between Emotional Intelligence and Job Satisfaction among Westcol Fel lecturers. Master's thesis. South Africa: University of Johannesburg. (Unpublished).

Cooper, C. A., Carpenter, D., Reiner, A., \& McCord, D. M. (2014). Personality and job satisfaction: Evidence from a sample of street-level bureaucrats. International Journal of Public Administration, 37(3), 155-162. https://doi.org/10.1080/01900692.2013.798810

Dawal, S. Z. M., \& Taha, Z. (2006). The effect of job and environmental factors on job satisfaction in automotive industries. International Journal of Occupational Safety and Ergonomics: JOSE, 12(3), 267-280.

https://doi.org/10.1080/10803548.2006.11076687

Dizgah, M. R., Chegini, M. G., \& Bisokhan, R. (2012). Relationship between job satisfaction and employee job performance in Guilan public sector. Journal of Basic and Applied Scientific Research, 2(2), 17351741.

Emdady, M., \& Bagheri, N. (2013). The relation between emotional intelligence and job satisfaction. European Journal of Experimental Biology, 3(1), 554-558. https://doi.org/10.5176/2251-1970_bizstrategy18.129

Fayombo, G. (2010). The relationship between personality traits and psychological resilience among the baribbean adolescents. International Journal of Psychological Studies, 2(2), 105-116. https://doi.org/10.5539/ijps.v2n2p105

Furnham, A., \& Christoforou, I. (2007). Personality traits, emotional intelligence, and multiple happiness. North American Journal of Psychology, 9(3), 439462. https://doi.org/10.2224/sbp.2003.31.8.815

Ganu, D., \& Kogutu, C. N. (2014). Effect of the big five personality traits on job satisfaction and organizational commitment in the healthcare industry: The case of Kenya. American Journal of Health Sciences, 5(2), 145-154. https://doi.org/10.19030/ajhs.v5i2.8964

Harms, P. D., \& Credé, M. (2010). Emotional intelligence and transformational and transactional leadership: A meta-analysis. Journal of Leadership \& Organizational Studies, $17, \quad 5-17$ https://doi.org/10.1177/1548051809350894 
Hazrati, E., Zabihi, R., \& Mehdizadeh, A. H. (2013). The relationship between emotional intelligence and personality features with job satisfaction status of male junior high school teachers in Islamshahr city. Journal of Educational and Management Studies, 3(3), 205-214. https://doi.org/10.1016/s09249338(13)76074-7

Ijaz, M., \& Khan, A (2015). The relationship of big five personality traits with job satisfaction among banking employees: A case study of Askari bank in district Peshawar. J. Appl. Environ. Biol. Sci., 5(5), 129-138.

Ismail, A., Yao, A., Yeo, E., Lai-Kuan, K., \& Soon-Yew, J. (2010). Occupational stress features, emotional intelligence and job satisfaction: An empirical study in private institutions of higher learning. E-Journal of Management Science, 16(5), 5-33. https://doi.org/10.1046/j.1365-2834.1998.00055.x

John, O. P., Donahue, E. M., \& Kentle, R. L. (1991). The Big Five Inventory- Versions $4 a$ and 54. Technical Report. Berkeley, CA: University of California at Berkeley, Institute of Personality and Social Research.

John, O. P., Naumann, L. P., \& Soto, C. J. (2008). Paradigm Shift to the Integrative Big Five Trait Taxonomy: History, Measurement, and Conceptual Issues. In O. P. John, R. W. Robins, \& L. A. Pervin (Eds.), Handbook of personality: theory and research (pp. 114-158). New York: Guilford Press.

Jorfi, H., Yaccob, H. F. B., \& Shah, I. M. (2011). The relationship between demographics variables, emotional intelligence, communication effectiveness, motivation, and job satisfaction. International journal of academic research in business and social sciences, $\quad 1(1), \quad 35-58$ https://doi.org/10.5121/ijmit.2011.3401

Kalyanasundaram, P., \& Lakshmi, M. (2013). A study on effect of emotional intelligence towards job satisfaction among nurses working in and around Coimbatore. Global Research Analysis, 2(10), 64-65.

King, R. T. (2014). Investigating Perceptions of Job Satisfaction in Older Workers Using Item Response Theory. Master's thesis. United States: Boeling Green University. (Unpublished).

Malik, M. E., Nawab, S., Naeem, B., \& Danish, R. Q. (2010). Job satisfaction and organizational commitment of university teachers in public sector of Pakistan. International journal of business and management, 5(6), 17. doi:10.5539/ijbm. v5n6p17

Mhlanga, T. S. (2012). An Investigation into the Relationship between Certain Personality Traits and Job Satisfaction: A Case of Selected Bank Employees in the Eastern Cape Province. Masters' thesis. University of Fort Hare, South Africa. (Unpublished). Mousavi, S. H., Yarmohammadi, S., Bani Nosrat, A., \& Tarasi, Z. (2012). The relationship between emotional intelligence and job satisfaction of physical education teachers. Annals of Biological Research, 3(2), 780-788.
Naderi Anari, N. (2012). Teachers: Emotional intelligence, job satisfaction, and organizational commitment. Journal of Workplace Learning, 24(4), 256-269. https://doi.org/10.1108/13665621211223379

Nasir, R., Mustaffa, M. B., Wan Shahrazad, W. S., Khairudin, R., \& Syed Salim, S. S. (2011). Parental support, personality, self-efficacy as predictors for depression among medical students. Pertanika Journal Social Science and Humanities, 19(5), 9-15.

Nawi, N. H. M., Marof, R., Shazia, I. H., \& Anuar, D. (2015). Big-five personality traits and its effect on emotional intelligence among public school personnel in Malaysia. Southeast Asia Psychology Journal, 3, 114.

Naz, S., Rehman, S., \& Saqib, H. (2013). The relationship between job satisfaction and personality trait among bank employees. Far East Journal of Psychology and Business, 11(3), 57-72.

Ngah, R., Jusoff, K., \& Abdul Rahman, Z. (2009). Emotional intelligence of Malaysian academia towards work performance. International Education Studies, 2(2), 103-112. https://doi.org/10.5539/ies.v2n2p103

Noordin, F., \& Jusoff, K. (2009). Levels of job satisfaction amongst Malaysian academic staff. Asian Social Science, $\quad 5(5), \quad 122-128$. https://doi.org/10.5539/ass.v5n5p122

Papathanasiou, S., \& Siati, M. (2014). Emotional intelligence and job satisfaction in_Greek banking sector. Research in Applied Economics, 6(1), 225-239. doi:10.5296/rae. v6i1.5050

Platsidou, M. (2013). Trait emotional intelligence predicts happiness, but how? An empirical study in adolescents and young adults. International Journal of Wellbeing, 3(2), 197-209. doi: 10.5502/ijw. v3i2.6

Psilopanagioti, A., Anagnostopoulos, F., Mourtou, E., \& Niakas, D. (2012). Emotional intelligence, emotional labour, and job satisfaction among physicians in Greece. BMC Health Services Research, 12, 463. https://doi.org/10.1186/1472-6963-12-463

Schutte, N. S., \& Malouff, J. M. (2011). Emotional intelligence mediates the_relationship between mindfulness and subjective well-being. Journal of Personality and Individual Differences, 50(7), 11161119. doi: 10.1016/j.paid.2011.01.037

Schutte, N. S., Malouff, J. M., \& Bhullar, N. (2009). The assessing emotions scale. C. Stough, D. Saklofske \& J. Parker (Eds.), The assessment of emotional intelligence (pp. 119-135). New York: Springer Publishing.

Schutte, N. S., Malouff, J. M., \& Thorsteinsson, E. B. (2013). Increasing emotional intelligence through training: Current status and future directions. The International Journal of Emotional Education, 5(1), 56-72.

Shooshtarian, Z., Ameli, F., \& Amini Lari, M. (2013). The effect of labor's emotional intelligence on their job satisfaction, job performance and commitment. 
Iranian Journal of Management Studies (IJMS), 6(1), 27-43. Doi.10.22059/IJMS.2013.30123

Smith, P. C., Kendall, L. M., \& Hulin, C. L. (1969). The measurement of satisfaction in work and retirement. Chicago: Rand McNally.

Tesdimir, M. Z., Zaheer Asghar, M., \& Saeed, S. (2010). Study of the Relationship Personality Traits and Job Satisfaction among Professional Pales Representatives in the Pharmaceutical Industry in Turkey. In $2^{\text {nd }}$ International Conference on Business Management.

Therasa, C., \& Vijayabanu, C. (2014). The impact of big five personality traits and positive psychological strengths towards job satisfaction: A review. Periodica Polytechnica Social and Management Science, 1-9. https://doi.org/10.3311/ppso.7620

Wan Ahmad, W. I., \& Abdurahman, S. M. (2015). Job satisfaction among academic staff of universiti Utara Malaysia: A work environment perspective. Mediterranean Journal of Social Sciences, 7(3), 251256. Doi: 10.5901/mjss. 2015.v6n3s2p251

Yahaya, A., Yahaya, N., Bon, A. T., Ismail, S., \& Noor, N. M. (2012). The relationship between big five personality with work motivation, competitiveness and job satisfaction. Elixir Psychology, 44, 7454-7461. https://doi.org/10.2139/ssrn.2866498 